DOI: $00.0000 / 0000000.0000000$

BY YOGESH DWIVEDI AND ZAHIR IRANI

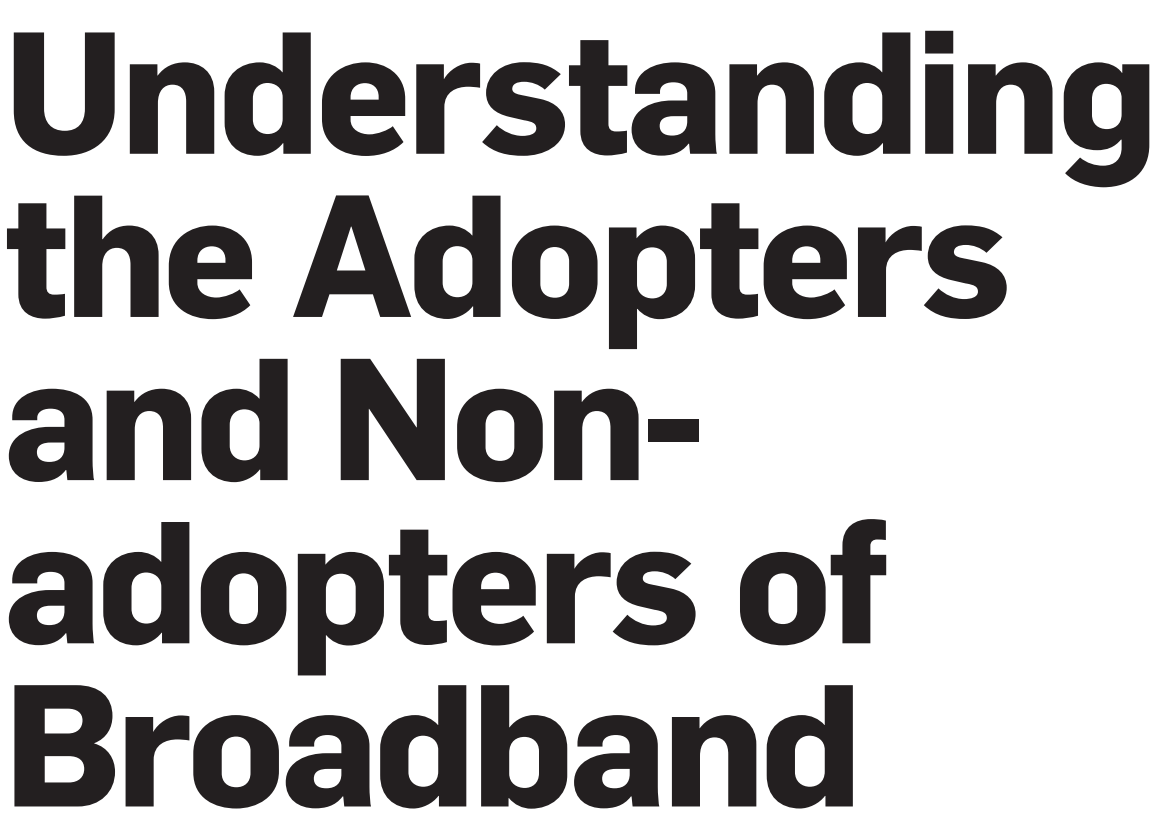

BROADBAND CONNECTIVITY IS CONSIDERED a significant driver in exploiting the full potential of electronic commerce within an information economy, which in turn is resulting in significant gains of international competitiveness at a national level. ${ }^{9}$ Therefore, encouraging businesses and homeowners to adopt broadband connectivity and thereby increasing penetration rates have been a prime policy-issue in many countries. ${ }^{9}$ Despite policy level mandates by some Governments to motivate gains in broadband diffusion, rates and levels of support differ greatly. Such policy decisions appear now to be contributing towards a digital divide, where for example, some countries such as South Korea (25.5 subscribers per 100 inhabitants) and The Netherlands (22.5 subscribers per 100 inhabitants) have reached steady state, whilst others such as Greece (0.8 subscribers per 100 inhabitants) and Mexico (1.0 subscribers per 100 inhabitants) represent much lower levels of penetration on the OECD list. ${ }^{6}$ Similarly, a recent report from the broadband think tank 'Point Topic' suggests heterogeneous adoption pattern and an emerging digital divide between urban and rural populations in the U.K. ${ }^{7}$

A contributing factor towards initial increases in U.K broadband residential subscriber numbers was considered due to strong competition amongst Internet Service Providers (ISPs) and a substantial reduction in the monthly subscription fee. These factors have now stabilized and are therefore less likely to contribute towards further increases in broadband adoption. However, the diffusion literature suggests that economic factor alone cannot determine adoption rates of an innovation. ${ }^{8}$ Similarly, Brown and Venkatesh ${ }^{2}$ argued, "when determining the demand of an innovation it is important to consider whether or not price is the most important barrier to household adoption and whether other barriers exist that are currently being ignored." It would therefore appear that there are human, organisation, technical and financial factors associated with broadband adoption, with Sawyer et al., ${ }^{9}$ explaining that, "The differential rates of use and growth, coupled with geographic disparity, suggests that understanding broadband and mobile connectivity is a complex milieu."

In seeking to better understand homogenous adoption and use of broadband, the authors will focus on factors other than subscription fee levels that are well understood by the commercial sector sales and marketing. Instead, the authors will examine the factors for understanding broadband adoption decisions at a household consumer level. We present the findings from a robustly administered broadband consumer survey that examined drivers and barriers of broadband adoption in the United Kingdom through exploring factors such as relative advantage, utilitarian outcomes, hedonic outcomes, social influence, knowledge, skills and resources.

In the study presented by Brown and Venkatesh, ${ }^{2}$ it was suggested that a different combination of factors are likely to be salient for different adopter categories (such as innovator-2.5\%, early 
adopters-13.5\%, early majority-34\%, late majority-34\% and laggards-16\%). ${ }^{2,8}$ According to OECD statistics6 broadband adoption in the UK (13.5 subscribers per 100 inhabitants) is in transition from early adopters to an early majority stage. This is also the case for many other European countries, such as Austria, Germany and France, and similarly for the United States of America. We proffer that factors likely to be salient for this adoption category are relative advantage, utilitarian outcomes, social influence and resources. Hereafter, we briefly describe our assumption about factors included in this study and their definitions and items as presented in Table 1.

Relative Advantage. This factor is considered as an important predictor for determining the rate of adoption. ${ }^{8}$ After launching an innovation to market, the time uncertainty period about its relative advantage become less as the consumers becomes more aware about its benefits, impact and usefulness. ${ }^{8}$ Therefore, it is likely that the information about relative advantage of broadband has been diffused through social networks. ${ }^{8}$ Hence, we propose relative advantage as a salient factor for consumer adoption of broadband.

Utilitarian Outcomes. This factor is associated with the utility of benefits that can be obtained from broadband and to know for what purpose the consumer of the innovation can exploit it in the household environment. ${ }^{2,3}$ The authors therefore propose utilitarian outcomes as a salient factor for understanding broadband adoption.

Hedonic Outcomes. This factor is related with the entertainment utility of the broadband..$^{2,3}$ It is propagated that the perceived hedonic outcome of both broadband and narrowband adoption is less likely to be a salient factor. A possible reason for this is the recent legal restriction against freeloading of music from the Internet. Freeloading and peer-to-peer online sharing of music is considered similar to software piracy. ${ }^{1}$ A study that examined the relationship between regulations, information technologies and human behaviour found that regulation does affect the human behaviour of file sharing in peer-topeer application environments. ${ }^{4}$ Therefore, such legal regulation is likely to inhibit consumers to realise entertainment potential of broadband.

\begin{tabular}{|c|c|}
\hline FACTOR & DEFINITION OF FACTOR/LIST OF DETAILED FACTOR \\
\hline \multirow[t]{5}{*}{ 1. Relative } & $\begin{array}{l}\text { The degree to which broadband Internet is perceived as being better than its predecessor } \\
\text { narrowband Internet }{ }^{8} \text {. }\end{array}$ \\
\hline & Broadband has an advantage over dial-up because it offers faster access to Internet \\
\hline & $\begin{array}{l}\text { Broadband has an advantage over dial-up because it provides faster download of files } \\
\text { from Internet }\end{array}$ \\
\hline & Broadband has an advantage over dial-up because it offers an always-on access to Internet \\
\hline & $\begin{array}{l}\text { Broadband has an advantage over dial-up because it frees up the phone line whilst } \\
\text { connected to the Internet }\end{array}$ \\
\hline \multirow{11}{*}{$\begin{array}{l}\text { 2. Utilitarian } \\
\text { Outcomes (UO) }\end{array}$} & The extent to which using broadband enhances the effectiveness of household activities ${ }^{2,3}$. \\
\hline & $\begin{array}{l}\text { Broadband can be useful to find educational materials and accessing library resources } \\
\text { at home }\end{array}$ \\
\hline & Broadband can be useful for distance learning \\
\hline & Broadband can be helpful to perform work/job-related tasks at home \\
\hline & Broadband will help me communicate better via email, chat, Web cam \\
\hline & Broadband can help in performing personal and household activities i.e. online shopping \\
\hline & Broadband can help in performing personal and household activities i.e. information search \\
\hline & Broadband can be helpful to establish and operate a home business \\
\hline & Broadband can help children to do their homework \\
\hline & Subscribing to broadband is compatible with most aspects of my everyday life \\
\hline & Overall broadband will be useful to me and other members in the family \\
\hline \multirow{5}{*}{$\begin{array}{l}\text { 3. Hedonic } \\
\text { Outcomes (HO) }\end{array}$} & The pleasure derived from broadband use 2,3 \\
\hline & I will enjoy using broadband to listen to and download music \\
\hline & I will enjoy using broadband to watch to and download movies \\
\hline & I will enjoy using broadband to play online games \\
\hline & I will enjoy using broadband to play online gambling/casino \\
\hline \multirow[t]{4}{*}{$\begin{array}{l}\text { 4. Social } \\
\text { Influence (SI) }\end{array}$} & $\begin{array}{l}\text { The extent to which members of a social network such as friends and family influence one } \\
\text { another behaviour }{ }^{2,3}\end{array}$ \\
\hline & $\begin{array}{l}\text { My friends think that I should subscribe to (or continue the current subscription) } \\
\text { broadband at home }\end{array}$ \\
\hline & $\begin{array}{l}\text { My colleagues think that I should subscribe to (or continue the current subscription) } \\
\text { broadband }\end{array}$ \\
\hline & $\begin{array}{l}\text { My family members think that I should subscribe to (or continue the current } \\
\text { subscription) to broadband }\end{array}$ \\
\hline \multirow{5}{*}{$\begin{array}{l}\text { 5. Resources } \\
\text { (R) }\end{array}$} & Resources is defined as the perceived level of resources when subscribing to broadband ${ }^{2,3,8}$ \\
\hline & My annual household income level is enough to afford subscribing to broadband \\
\hline & It is not too costly to purchase a new computer or to upgrade my old computer \\
\hline & It is not too costly for me to subscribe to broadband at its current subscription fee \\
\hline & I would be able to subscribe to broadband if I wanted to \\
\hline \multirow[t]{4}{*}{$\begin{array}{l}\text { 6. Knowledge } \\
\text { (K) }\end{array}$} & $\begin{array}{l}\text { Knowledge is defined as the perceived level of knowledge about broadband Internet, its } \\
\text { risks and benefits } 2,3,8 \text {. }\end{array}$ \\
\hline & I do not have difficulty in explaining why adopting broadband may be beneficial \\
\hline & I know how broadband is different from dial-up/narrowband Internet \\
\hline & I know the benefits that broadband offer and cannot be obtained by dial-up/narrowband \\
\hline \multirow[t]{4}{*}{ 7. Skills (Sk) } & $\begin{array}{l}\text { Skill is defined as the perceived ability or skill to operate computers and the broadband } \\
\text { without the assistance of others } 2,3,8\end{array}$ \\
\hline & I would feel comfortable using the Internet on my own \\
\hline & Learning to operate the Internet is easy for me \\
\hline & I clearl \\
\hline
\end{tabular}

Social Influence. Innovation literature suggest that later adopters are likely to wait for innovation to be well established in the market place and supported by positive messages from their peers before taking any decision to adopt. Hence, we expect social influence to be a salient factor in the adoption of broadband. ${ }^{2,3,8}$

Knowledge and Skill. Broadband consumers are likely to have used the Internet via narrowband at home or else other places such as the office or in educational institutions. Therefore, such individuals are expected to have a strong perception of knowledge, as well having the skills required to use broadband. ${ }^{8}$ In other words, skill and knowledge should be considered less of a salient factor for adopters of broadband.

Perceived Resources. Innovation literature suggests that the innovator and early adopters generally belongs to affluent section of society, hence, avail- 


\begin{tabular}{|c|c|c|c|c|c|c|c|}
\hline \multirow{3}{*}{$\begin{array}{c}\text { Type of Connection } \\
\text { Factors } \\
\end{array}$} & \multirow{2}{*}{\multicolumn{2}{|c|}{$\begin{array}{l}\text { Adopters } \\
\text { Broadband } \\
(\mathbf{N}=\mathbf{2 0 7})\end{array}$}} & \multicolumn{4}{|c|}{ Non-adopters } & \multirow{3}{*}{\begin{tabular}{l|} 
Difference \\
Sig./Non Sig.
\end{tabular}} \\
\hline & & & \multicolumn{2}{|c|}{$\begin{array}{c}\text { Narrowband } \\
(\mathrm{N}=101)\end{array}$} & \multicolumn{2}{|c|}{$\begin{array}{c}\text { No Access } \\
(\mathbf{N}=\mathbf{5 0})\end{array}$} & \\
\hline & $\% *$ & $\mathrm{R}$ & $\% *$ & $\mathrm{R}$ & $\% *$ & $\mathrm{R}$ & \\
\hline RA & 97.1 & 1 & 90.1 & 1 & 80.0 & 1 & Significant \\
\hline UO & 86.5 & 3 & 62.4 & 4 & 54.0 & 4 & Significant \\
\hline HO & 17.9 & 7 & 14.9 & 7 & 24.0 & 7 & Not Significant \\
\hline SI & 56.5 & 6 & 41.6 & 6 & 34.0 & 5 & Significant \\
\hline $\mathbf{R}$ & 76.3 & 5 & 51.5 & 5 & 30.0 & 6 & Significant \\
\hline $\mathbf{K}$ & 82.6 & 4 & 72.3 & 3 & 60.0 & 3 & Significant \\
\hline SK & 93.2 & 2 & 86.1 & 2 & 78.0 & 2 & Significant \\
\hline \multicolumn{8}{|c|}{$\begin{array}{l}\text { *Percentage of Respondents Rated Factors equal or above } 5 \text { on } 7 \text {-point scale where: } \mathbf{7}=\text { Extremely agree, } \mathbf{6}=\text { Quite } \\
\text { agree, } \mathbf{5}=\text { Slightly agree, } \mathbf{4}=\text { Neutral, } \mathbf{3}=\text { Slightly disagree, } \mathbf{2}=\text { Quite disagree, } \mathbf{1}=\text { Extremely disagree } \\
\mathbf{R}=\text { Rank }\end{array}$} \\
\hline
\end{tabular}

able resources is not a constraint for them to adopt an innovation. In contrast, later adopters and non-adopters are more likely to belong from less affluent section of society and likely to be inhibited to adopt an innovation if they perceive they lack required level of resources. ${ }^{2,3,8}$ Therefore, we expect that the perceived resources (income level) and perceived high cost (monthly subscription fee) likely to be salient factor for later adopters and non-adopters.

Broadband Adopters vs. Non-adopters. For all seven factors described above we expect that broadband adopters will have a significantly higher perception on aforementioned factors than non-adopters (i.e. narrowband consumers and respondents with no Internet access at home).

To examine the assumptions presented, we undertook a nationwide household postal survey. The data were collected employing a self-administered postal questionnairewith close-ended,multiple and 7 point Likert scale type questions. To protect against bias and to ensure the veracity of data generated, numerous check-questions were embedded within the questionnaire. The approach of developing and validating the instrument that was employed to collect data in this research was similar to previous study5 that was focused upon instrument development process. We sent a covering letter, questionnaire and a pre-paid return envelop to 1600 randomly selected households in the U.K. 358 respondents completed the entire questionnaire and returned usable responses that help us to obtain response rate of about $22.4 \%$. This was after excluding 25 responses that were unusable due to incomplete responses and undelivered due to change of address. Of the 358 respondents, 207 represented the adopters of broadband and 151 the non-adopters. Of the 151 non-adopters category, 101 had a narrowband connection and 50 stated that they do not have any means of Internet access at home.

\section{Empirical Findings}

Table 2 illustrates the percentage of respondents who rated each factor equal or above 5 on the 7-point scale. The Findings suggest that the respondents considered relative advantage as the most salient factor whilst hedonic outcomes were considered as being the least important reason when subscribing to broadband.

Relative Advantage. $97 \%$ of subscribers to broadband and $90 \%$ of narrowband subscribers agreed that the advantages offered by broadband over narrowband as being important when consideration subscription. In contrast, only $80 \%$ of respondents from no-access category agreed that relative advantage is an important one if a decision about broadband subscription was being taken. Overall, the largest percentage of respondents from both adopter and non-adopter categories considered it important, which makes it the first salient factor amongst seven examined in this study.

Utilitarian Outcomes. Third largest percentage $(86.5 \%)$ of broadband consumers considered utilitarian outcomes an important factor when making adoption decisions. Non-adopters including both narrowband consumers (62.4\%) and respondents with no-access (54\%) considered it an important factor.

Hedonic Outcomes. Least percentage of survey respondents from both adopter (17.9\%) and non-adopter categories including narrowband consumers (14.9\%) and respondents with no access $(24 \%)$ agreed that the hedonic use of broadband is an important factor for making adoption decisions. This suggests that from the perspective of both adopters and non-adopters, hedonic outcomes are the least salient factor for making adoption decisions.

Social Influence. $56.5 \%$ of subscribers agreed that social influence is an important factor when making broadband subscription decisions. Comparatively, less percentage of respondents from narrowband $(41.6 \%)$ and no-access $(34 \%)$ categories considered it an important factor.

Perceived Resources. 76.3\% of broadband consumers perceived that subscription fee is not a problem, and that they have sufficient financial resources. Hence, it is not a barrier for them to subscribe to broadband. Contrastingly, $51.5 \%$ of narrowband consumers and only $30 \%$ of respondents of the no-access category perceived that subscription fee was not a problem and they have resources to subscribe. Data therefore suggests that this factor is salient for the future adoption of broadband.

Knowledge and Skills. $82.6 \%$ of broadband consumers and $72.3 \%$ of narrowband consumers but only $60 \%$ of respondents with no-Internet access at home agreed that they have the requisite knowledge about benefits that broadband offers. Hence, it would appear to be more salient for non-adopters than adopters. $93.2 \%$ of broadband and $86.1 \%$ of narrowband consumers but only $78 \%$ of respondents with noInternet access at home agreed that they have sufficient skill to use the In- 
ternet and hence, it is not a barrier that might inhibit broadband adoption.

Table 2 also provides the results of the ANOVA, which tested the significance of difference among three groups (broadband, narrowband and no access categories) on seven factors included in the study. The findings indicate that with the exception of hedonic outcomes, respondents from three groups differ significantly on the mean score for the remaining six factors.

\section{Implications for the ISPs}

The findings presented in this paper raise a number of issues, with implications emerging that prove imperative in assisting both policy makers and ISPs during their strategy to increase consumer adoption of broadband. The effort of ISPs to increase and sustain broadband subscriber numbers needs to focus on the factors most salient to potential consumers (narrowband consumers and respondents with noaccess). For example, since relative advantage is found to be the strongest factor, it suggests that ISPs should provide broadband services to consumers in such a package that would illustrate a clear advantage in terms of both speed and access convenience, over narrowband connection. However, strategies of some ISPs is to reduce the price but also cap the speed, which may erode the relative advantage perceived by the consumer and therefore, in effect, counteract a strategy of increasing penetration.

All three groups of consumers considered utilitarian outcomes as an important factor for adopting broadband. However, the percentage of consumers from narrowband and no-access categories considering it important is lesser than the broadband ones. This indicates that non-adopters are not fully aware of the usefulness of broadband for household purposes and hence, they are slow in adopting it. Therefore, marketing strategies by ISPs should be pitched to inform consumers about usefulness of broadband for household and individual purposes. This should complement current trends of attracting consumers by a reduction in subscription fee, which alone may not work for much longer, as the consumer group that is sensitive to this factor is reaching saturation point.

Although broadband has the poten- tial to offer strong medium of entertainment (streaming and downloading music and movie) to consumers, the least percentage of respondents considered hedonic outcome as an important factor when considering the subscription of broadband. A possible reason could be the regulations surrounding the free downloading of files. Similar to usefulness, consumers also should be made aware about recent regulations and, the available entertainment services. Advertising campaigns from both ISPs and content providers should aim to develop positive attitude of consumers towards paid entertainment services and applications utilizing broadband for high-speed connectivity.

Perceived resources to subscribe broadband is also an important factor for both narrowband consumers and respondents with no-Internet access. This has implications for both ISPs and policy makers, where for instance, ISPs have to think about more consumer centric services and, alternative price plans so that all consumers who want to subscribe to broadband services would be able to do so. Policy makers have to provide alternative access points for broadband access where lower income groups can use high speed Internet. It may help to increase behavioural intention to adopt broadband and therefore encourage overall adoption and diffusion rates as well as motivating eparticipation and thus, supporting the erosion of the digital divide Findings presented indicate that the majority of respondents from all three groups possess a higher perception of skill and knowledge about the benefits of broadband. This suggests that these two factors have less of a salient role in inhibiting broadband adoption, hence, less attention is required by policy makers in these two areas.

\section{Conclusion}

We examined seven factors extrapolated from the literature to better understand the reasons motivating the adoption of broadband by household consumers. Findings illustrate that adopters and non-adopters differs in terms of factors that they think are important for making decision to subscribe broadband. The highly competitive UK broadband industry has largely pursued a strategy of high-speed access and a reduction in subscription fee to increase its consumer base. Our findings suggest that there are a number of factors other than speed of Internet and subscription fee that are perceived by the consumer as being important, and in some cases more so that speed and cost. Therefore, it is vital for the broadband industry to target potential consumers including narrowband subscribers and those with no-Internet access through not only reducing subscription fee and increasing access speed but also by convincing them of it's usefulness for the purpose of household and entertainment utility.

\section{References}

1. Bhattacharjee, S., Gopal, R.D. and Sanders, G.L. Digital music and online sharing: software piracy 2.0 ? Comm ACM 46, 7 (2003) 107-111.

2. Brown, S.A and Venkatesh, V. Bringing non-adopters along: The challenge facing the PC industry. Comm. ACM 46 4, (2003) 76-80.

3. Brown, S.A and Venkatesh, V. Model of adoption of technology in households: A baseline model test and extension incorporating household life cycle. MIS Quarterly 29, 3 (2005) 399-426.

4. Mlcakova, A. and Whitley, E. A. Configuring peer-topeer software: An empirical study of how users react to the regulatory features of software. European Journal of Information Systems 13, 1 (2004) 95-102.

5. Moore, G.C. and Benbasat, I. Development of an instrument to measure the perceptions of adopting an information technology innovation. Information Systems Research 2. 3 (1991) 192-212.

6. Organisation for Economic Cooperation and Development. OECD Broadband Statistics, June 2005. http://www.oecd.org/document/16/0,2340,en_2649_3 4225_35526608_1_1_1_1,00.html\#data2004

7 Point Topic Analysis of Broadband Take-up. Jan. 2006: http://www.point-topic.com/content/dslanalysis/ BBUSDeepeningDigitalDivide060117.htm

8. Rogers, E.M. Diffusion of Innovations, 4th Ed., The Free Press, NY, 1995.

9. Sawyer, S., Allen, J.P. and Lee, H. Broadband and mobile opportunities: a socio-technical perspective. J. Information Technology 18 (2003) 121-136.

Yogesh Kumar Dwivedi is a Lecturer in Information Systems at the School of Business and Economics, University of Wales Swansea, U.K.

Professor Zahir Irani is the Head of the Business School at Brunel University, U.K.

(C) 2009 ACM 0001-0782/09/0100 $\$ 5.00$ 